\title{
PENGGUNAAN ZAT WARNA TEKSTIL PADA LATEKS KARET ALAM SEBAGAI BAHAN PELAPIS KAIN KANVAS WATER REPELLENT
}

\author{
THE USE OF TEXTILE DYES IN NATURAL RUBBER LATEX AS A \\ COATING MATERIAL CANVAS CLOTH WATER REPELLENT
}

\author{
Luftinor \\ Balai Riset dan Standardisasi Industri Palembang \\ JI Perindustrian II KM 9 No 12 Palembang \\ e-mail : luftinor@yahoo.co.id
}

Diterima: 20 Agustus 2019; Direvisi: 11 September - 26 November 2019; Disetujui: 16 Desember 2019

\begin{abstract}
Abstrak
Penelitian ini bertujuan untuk mendapatkan zat warna tekstil yang tepat dan dapat digunakan pada proses pewarnaan lateks karet alam sebagai bahan pelapis pada pembuatan kain kanvas water repellent. Penelitian ini menggunakan rancangan acak lengkap 2 faktorial dengan memvariasikan tiga macam jenis zat warna tekstil yaitu zat warna procion, zat warna pigmen dan zat warna basis serta memvariasikan konsentrasi zat warna dalam tiga tingkatan yaitu $5 \mathrm{~g}$, $10 \mathrm{~g}$ dan $15 \mathrm{~g}$. Parameter yang diuji berupa kecerahan warna, ketahanan luntur warna, daya tahan air kekuatan rekat, kekuatan tarik, mulur dan ketahanan sobek. Semakin tinggi konsentrasi zat warna yang digunakan pada kompon lateks sampai pada batas tertentu warna kain kanvas water repellent yang dihasilkan semakin cerah, akan tetapi sifat fisika lainnya seperti ketahanan luntur warna, daya tahan air, kekuatan rekat, kekuatan tarik, mulur dan kekuatan sobek cenderung tidak berbeda nyata. Hasil terbaik diperoleh pada formula $\mathrm{V}$ dengan menggunakan zat warna pigmen, mendapatkan nilai kecerahan warna 4,8 (baik), katahanan luntur warna terhadap pencucian 4 (baik) untuk perubahan warna , 4-5 (baik) untuk penodaan warna, Ketahanan luntur warna terhadap gosokan 4-5 (baik) untuk gosokan kering, 4 (baik) untuk gosokan basah, daya tahan air 79,8 mBar, kekuatan rekat 1,2 kg/cm, kekuatan tarik $80,6 \mathrm{~kg}$ dan $77,8 \mathrm{~kg}$ untuk lusi dan pakan, mulur $41,2 \%$ dan $18,8 \%$ untuk lusi dan pakan, kekuatan sobek $19,5 \mathrm{~kg}$ dan 18,2 kg untuk lusi dan pakan.
\end{abstract}

Kata kunci: basis, kain kanvas, lateks alam, pigmen, procion

\begin{abstract}
This study aims to obtain the right textile dyes and can be used in the process of coloring natural rubber latex as a coating material in making water repellent canvas fabric. This study uses a 2 factorial complete randomized design by varying three types of textile dyes namely procion dyes, pigment dyes and base dyes as well as varying the concentration of dyes in three levels namely $5 \mathrm{~g}, 10 \mathrm{~g}$ and $15 \mathrm{~g}$. The parameters tested were color brightness, color fastness, water resistance, adhesive strength, tensile strength, elongation and tear resistance. The higher the concentration of dyes used in the latex compound to a certain extent the color of the water repellent canvas fabric produced brighter, but other physical properties such as color fastness, water resistance, adhesive strength, tensile strength, stretch and tear strength tend not to significantly different. The best results are obtained in formula $V$ by using pigment dyes, obtaining a color brightness value of 4.8 (good), color fastness to washing 4 (good) for discoloration, 4-5 (good) for color staining, color fastness to rubbing 4-5 (good) for dry rubbing, 4 (good) for wet rubbing, water resistance $79.8 \mathrm{mBar}$, adhesive strength $1.2 \mathrm{~kg} / \mathrm{cm}$, tensile strength $80.6 \mathrm{~kg}$ and $77.8 \mathrm{~kg}$ for warp and feed, stretched $41.2 \%$ and $18.8 \%$ for warp and feed, tear strength $19.5 \mathrm{~kg}$ and $18.2 \mathrm{~kg}$ for warp and feed.
\end{abstract}

Keywords: base, canvas fabric, natural latex, pigment, procion

\section{PENDAHULUAN}

Hasil utama tanaman karet adalah lateks yang dapat membuat berbagai macam produk, seperti ban kendaraan bermotor, selang karet, komponen otomotif, sarung tangan, peralatan kesehatan/farmasi, peralatan rumah tangga dan lain-lainnya

Karet alam merupakan cairan getah dari tumbuhan Hevea brasiliensis yang merupakan polimer alam dengan monomer isoprene (Richard, 2009). Polimer karet alam ini terdiri dari 97\% polimer cis-1,4 polyisoprene (Stagg, 2007)). Lateks didefinisikan sebagai suatu disperse yang stabil dari substansi polimer, yaitu polimer karet dalam cairan serum yang berisi berbagai macam senyawa organik dan anorganik (Blackley, 2011) dan (Noble 2003)

Menurut Morton (2008) dan Stevens (2006) lateks alam mengandung karet yang merupakan makromolekul polyisoprena $(\mathrm{C} 5 \mathrm{H} 8) \mathrm{n}$ dengan $\mathrm{n}$ berkisar antara 3.000 
sampai 15.000, yang bergabung dengan ikatan kepala ekor (head to tail). Konfigurasi polimer ini adalah cis dengan susunan ruang yang teratur, sehingga rumus karet alam adalah 1,4-cis-polyisoprene.

Dalam usaha untuk meningkatkan harga bahan baku karet, maka perlu dilakukan penelitian-penelitian dengan memanfaatkan dan meningkatkan penggunaan bahan baku karet alam untuk pembuatan produk-produk hilir karet maupun pembuatan produk baru yang sebelumnya belum menggunakan bahan baku karet alam, salah satunya adalah kain water repellent.

Kain water repellent merupakan kain yang permukaannya dapat menahan air dan udara dan dapat menahan tekanan hidrostatik dari kolom air, teknik pengerjaannya sangat tergantung pada macam serat, misalnya kain dari serat selulosa, wol, asetat, nylon, terylene dan akrilat. (Suparman, et al, 1997).

Kain kanvas adalah kain berat dan kuat ditenun dengan anyaman polos, benangnya dapat tunggal,rangkap maupun gintir dibuat dari serat kapas, flax, rami, jute, sintetik atau campurannya. Kain kanvas terbagi dalam tiga golongan, yaitu kanvas berat digunakan untuk keperluan industri, kanvas sedang untuk, layar, kantong pos, tas, penutup truk, keperluan militer seperti tenda, ransel dan lain-lainnya, kanvas ringan dipergunakan untuk sepatu, payung dan peralatan rumah tangga (Hudson, 2011).

Beberapa jenis kain kanvas diberi bahan pelapis pada permukaannya agar dapat menahan air (water repellent), juga untuk menarik secara estetika dan memiliki ketahanan kimiawi dan fisik yang lebih baik dibandingkan dengan meterial biasa sesuai dengan kegunaannya. Bahan yang sudah biasa digunakan untuk pelapis kain kanvas ada beberapa jenis bahan sintetis, seperti garam alumunium, garam zirconium, aminoplast dan silicon (Muhamed, 2017).

Pada penelitian terdahulu telah digunakan lateks karet alam sebagai bahan pelapis untuk pembuatan kain kanvas water repellent (Luftinor, 2015). Guna memperindah kenampakan kain kanvas water repellent dan menarik secara estetika, maka perlu pemberian zat warna pada bahan lateks yang akan digunakan sebagai bahan pelapis, pada penelitian ini dicoba menggunakan 3 jenis zat warna tekstil yaitu zat warna procion, zat warna pigmen dan zat warna basis.
Zat Warna procion merupakan zat warna yang mengandung gugus procion dan dapat mengadakan reaksi dengan serat pada kondisi tertentu, sehingga zat warna tersebut ketahanan cucinya sangat baik (Sunarto, 2008). Zat warna pigmen merupakan zat warna yang dapat digunakan untuk semua jenis bahan tekstil sehingga banyak digunakan, zat warna ini tidak mempunyai gugus pelarut atau gugus yang dapat berikatan dengan serat. Sifat zat warna pigmen hanya menempel saja pada permukaan kain dengan pengikat binder. Karena sifatnya hanya menempel saja maka hasil yang diperoleh mempunyai efek kaku. Untuk menghindari efek ini biasanya dalam resep yang digunakan ditambahkan zat pelembut (Djufri, et al, 1998). Zat warna pigmen umumnya digunakan pada proses pencapan/printing sehingga memerlukan pengental sebagai pembantu dalam proses pewarnaan. (Agus, et al, 2016). Zat warna basis merupakan garam-garam khlorida atau oksalat dari basa-basa organik, misalnya basa ammonium, oksonium, dan sering pula merupakan garam rangkap dengan seng khlorida. Khromofor dari zat warna ini terdapat pada kationnya. Warnanya yang dihasilkan cerah, akan tetapi ketahanan luntur warnanya kurang baik.(Hartanto dan Watanabe, 2003)

Pada penelitian ini telah dicoba menggunakan ketiga macam jenis zat warna tersebut pada bahan lateks alam cair ditambahkan bahan-bahan kimia lain, seperti ZMBT, ZDEC, ZnO, lonol, sulfur, $\mathrm{KOH}$ dan $\mathrm{TiO} 2$ sebagai bahan pelapis. Selain mengurangi subsidi impor, penggunaan lateks karet alam dapat dilakukan dengan teknologi dan peralatan yang sederhana serta biaya yang lebih murah sehingga dapat diterapkan oleh industry kecil (IKM).

Tujuan penelitian adalah untuk mendapatkan penggunaan zat warna tekstil dan formula yang tepat pada lateks karet alam ditambah bahan kimia lain sebagai bahan pelapis pada pembuatan kain kanvas water repellent yang mempunyai kecerahan warna dan ketahanan luntur warna, daya tahan air, ketahanan rekat, kekuatan tarik dan kekuatan sobek sesuai persyaratan mutu.

\section{METODE}

\section{Bahan dan Alat}

Bahan-bahan yang digunakan dalam penelitian ini terdiri dari bahan baku lateks 
alam dengan spesifikasi kadar jumlah padatan $61,25 \%$, kadar karet kering $60,43 \%$, kadar amoniak 0,68 \% dan kadar koagulum $0,039 \%$, kain kanvas dengan konstruksi anyaman plat, tetal lusi 42 helai/inch, tetal pakan 29 helai/inch, nomor benang lusi $\mathrm{Ne} 1$ 4, nomor benang pakan $\mathrm{Ne} 16$, zat warna procion, pigmen, basis, $\mathrm{KOH}$, ZDEC, ZMBT, IONOL, $\mathrm{ZnO}, \mathrm{TiO}_{2}$ Sulfur, Bentonit dan Darvan.

Sedangkan Peralatan yang digunakan terdiri dari pemutar guci (ball mill), mesin pengaduk (mixer), Screen, rakel, dan oven pengering.

\section{Metode Penelitian}

Penelitian dilakukan di laboratorium Balai Riset dan Standardisasi Industri Palembang, menggunakan Rancangan Acak Lengkap (RAL) dengan mempelajari hubungan antara faktor jenis zat warna $(A)$ : $A_{1}=$ zat warna procion , $A_{2}=$ zat warna pigmen dan $A_{3}=$ zat warna basis, dan faktor konsentrasi zat warna (B): $B_{1}=5 \mathrm{~g}$, $B_{2}=10 \mathrm{~g}$ dan $B_{3}=15 \mathrm{~g}$ terhadap sifat

Tabel 1. Formula Kompon Lateks

\begin{tabular}{|c|c|c|c|c|c|}
\hline \multirow[t]{2}{*}{ Bahan } & \multicolumn{5}{|c|}{ Formula } \\
\hline & $\mathrm{I}$ & II & III & IV & V \\
\hline KOH 10\% & $30 \mathrm{~g}$ & $30 \mathrm{~g}$ & $30 \mathrm{~g}$ & $30 \mathrm{~g}$ & 30 \\
\hline $\begin{array}{l}\text { ZDEC } 50 \% \\
\text { (disperse) }\end{array}$ & $9,6 \mathrm{~g}$ & $9,6 \mathrm{~g}$ & $9,6 \mathrm{~g}$ & $9,6 \mathrm{~g}$ & $9,6 \mathrm{~g}$ \\
\hline $\begin{array}{l}\text { ZMBT 50\% } \\
\text { (disperse) }\end{array}$ & $8,4 \mathrm{~g}$ & $8,4 \mathrm{~g}$ & $8,4 \mathrm{~g}$ & $8,4 \mathrm{~g}$ & $8,4 \mathrm{~g}$ \\
\hline $\begin{array}{l}\text { lonol } 50 \% \\
\text { (disperse) }\end{array}$ & $12 \mathrm{~g}$ & $12 \mathrm{~g}$ & $12 \mathrm{~g}$ & $12 \mathrm{~g}$ & $12 \mathrm{~g}$ \\
\hline $\begin{array}{l}\text { Sulfur } 50 \% \\
\text { (disperse) }\end{array}$ & $48 \mathrm{~g}$ & $48 \mathrm{~g}$ & $48 \mathrm{~g}$ & $48 \mathrm{~g}$ & $48 \mathrm{~g}$ \\
\hline $\begin{array}{l}\text { ZnO 50\% } \\
\text { (disperse) }\end{array}$ & $24 \mathrm{~g}$ & $24 \mathrm{~g}$ & $24 \mathrm{~g}$ & $24 \mathrm{~g}$ & $24 \mathrm{~g}$ \\
\hline $\begin{array}{l}\mathrm{TiO}_{2} \% \\
\text { (disperse) }\end{array}$ & $3 \mathrm{~g}$ & $3 \mathrm{~g}$ & $3 \mathrm{~g}$ & $3 \mathrm{~g}$ & $3 \mathrm{~g}$ \\
\hline $\begin{array}{l}\text { ZW procion } \\
\text { (disperse) }\end{array}$ & $5 \mathrm{~g}$ & $10 \mathrm{~g}$ & $15 \mathrm{~g}$ & & \\
\hline $\begin{array}{l}\text { ZW pigmen } \\
\text { (disperse) }\end{array}$ & & & & $5 \mathrm{~g}$ & $10 \mathrm{~g}$ \\
\hline Lateks & $1 \mathrm{It|}$ & $1 \mathrm{ltr}$ & $1 \mathrm{ltr}$ & $1 \mathrm{ltr}$ & $1 \mathrm{ltr}$ \\
\hline
\end{tabular}

Tabel 1. lanjutan

\begin{tabular}{|c|c|c|c|c|}
\hline \multirow[t]{2}{*}{ Bahan } & \multicolumn{4}{|c|}{ Formula } \\
\hline & VI & VII & VIII & IX \\
\hline KOH 10\% & $30 \mathrm{~g}$ & $30 \mathrm{~g}$ & $30 \mathrm{~g}$ & $30 \mathrm{~g}$ \\
\hline $\begin{array}{l}\text { ZDEC 50\% } \\
\text { (disperse) }\end{array}$ & $9,6 \mathrm{~g}$ & $9,6 \mathrm{~g}$ & $9,6 \mathrm{~g}$ & $9,6 \mathrm{~g}$ \\
\hline $\begin{array}{l}\text { ZMBT 50\% } \\
\text { (disperse) }\end{array}$ & $8,4 \mathrm{~g}$ & $8,4 \mathrm{~g}$ & $8,4 \mathrm{~g}$ & $8,4 \mathrm{~g}$ \\
\hline $\begin{array}{l}\text { lonol } 50 \% \\
\text { (disperse) }\end{array}$ & $12 \mathrm{~g}$ & $12 \mathrm{~g}$ & $12 \mathrm{~g}$ & $12 \mathrm{~g}$ \\
\hline $\begin{array}{l}\text { Sulfur } 50 \% \\
\text { (disperse) }\end{array}$ & $48 \mathrm{~g}$ & $48 \mathrm{~g}$ & $48 \mathrm{~g}$ & $48 \mathrm{~g}$ \\
\hline $\begin{array}{l}\text { ZnO 50\% } \\
\text { (disperse) }\end{array}$ & $24 \mathrm{~g}$ & $24 \mathrm{~g}$ & $24 \mathrm{~g}$ & $24 \mathrm{~g}$ \\
\hline $\begin{array}{l}\mathrm{TiO} 2 \\
\text { (disperse) } \\
\text { ZW procion } \\
\text { (disperse) }\end{array}$ & $3 \mathrm{~g}$ & $3 \mathrm{~g}$ & $3 g$ & $3 \mathrm{~g}$ \\
\hline $\begin{array}{l}\text { ZW pigmen } \\
\text { (disperse) }\end{array}$ & $15 \mathrm{~g}$ & & & \\
\hline $\begin{array}{l}\text { ZW basis } \\
\text { (disperse) }\end{array}$ & & $5 \mathrm{~g}$ & $10 \mathrm{~g}$ & $15 \mathrm{~g}$ \\
\hline Lateks & $1 \mathrm{ltr}$ & $1 \mathrm{Itr}$ & $1 \mathrm{ltr}$ & $1 \mathrm{ltr}$ \\
\hline
\end{tabular}

fisika kain kanvas water repellent seperti dapat dilihat pada Tabel 1 dan diagram alir proses seperti terlihat pada Gambar 1.

\section{Pembuatan Kompon Lateks}

Bahan-bahan kimia seperti ZDEC, ZMBT, IONOL ZnO, Sulfur, $\mathrm{TiO}_{2}$ dan zat warna masing-masing dibuat larutan dispersi dengan cara ditimbang sesuai dengan formula masing-masing kemudian dimasukkan kedalam guci dilengkapi dengan butiran peluru. Guci ditutup rapat dan diputar dalam alat ball mill selama 24 jam

Bahan-bahan kimia dan zat warna hasil dispersi dicampur dengan lateks pekat yang telah disentrifugasi ditambah $\mathrm{KOH}$ pada mesin mixer diaduk selama 30 menit, selanjutnya didiamkan selama 24 jam agar campuran lebih homogen sehingga terbentuk kompon lateks.

\section{Proses Pelapisan}

Proses pelapisan kompon lateks menggunakan alat cetak sesuai dengan ukuran sampel dan dengan menggunakan 
rakel, bahan pelapis diratakan ke seluruh permukaan kain

Kain water repellent merupakan kain yang permukaannya dapat menahan air dan udara dan dapat menahan tekanan hidrostatik dari kolom air, teknik pengerjaannya sangat tergantung pada macam serat, misalnya kain

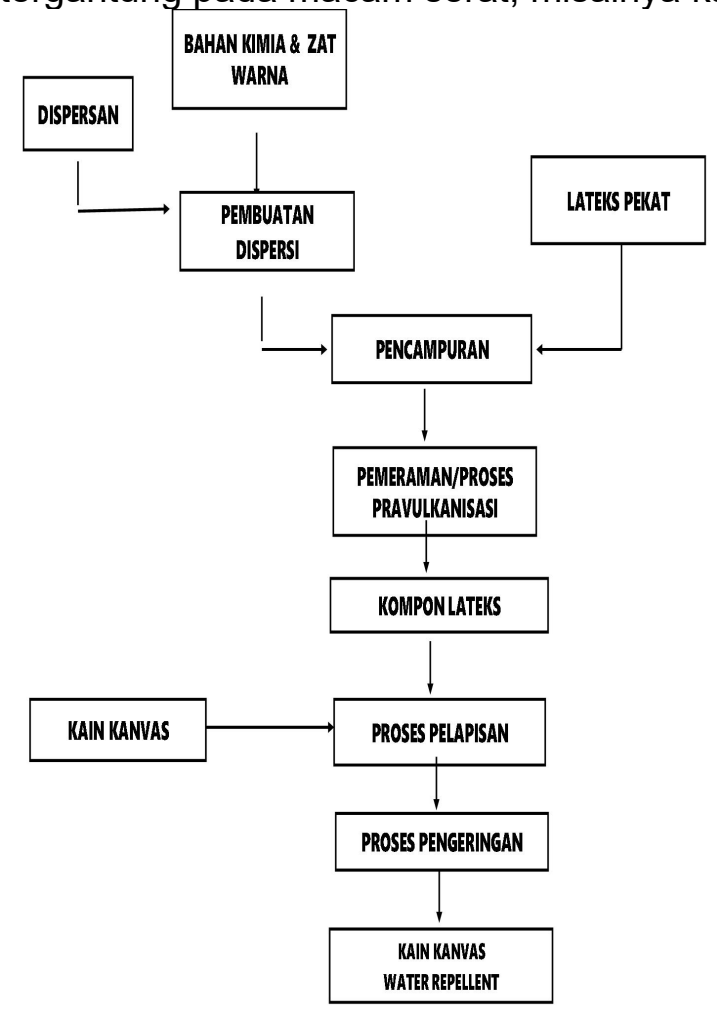

Gambar 1. Urutan Proses Pembuatan Kain kanvas water repellent

\section{Proses pengeringan}

Kain yang telah dilapisi kompon lateks selanjutnya dikeringkan dalam oven pengering masing-masing pada suhu 110 ${ }^{0} \mathrm{C}$ selama 15 menit

\section{Parameter yang Diuji}

Berupa uji kecerahan warna diamati secara visual, panelis sebanyak 5 orang dengan skor penilaian 5 = sangat cerah, $4=$ cerah, 3 = cukup cerah, 2 = kurang cerah dan $1=$ tidak cerah. Uji ketahanan untur warna terhadap pencucian dilakukan berdasarkan (SNI 08-0285-1989). Uji ketahanan luntur warna terhadap gosokan (SNI 08-02881989), Uji daya tahan air (SNI 08-0295-1989), Uji Kekuatan tarik dan mulur (SNI 08-02761989), Uji kekuatan sobek (SNI 08-03381989) dan Uji kekuatan rekat (ISO 24112017).

\section{HASIL DAN PEMBAHASAN}

\section{1, Kecerahan Warna}

Hasil pengujian terhadap kecerahan warna kain kanvas seperti terlihat pada histogram Gambar 2 sampai pada batas tertentu cenderung meningkat dengan bertambahnya konsentrasi zat warna, baik untuk zat warna procion, pigmen maupun zat warna basis.

Histogram pada Gambar 2 dapat dilihat bahwa pada konsentrasi larutan zat warna pigmen $5 \mathrm{~g} / \mathrm{l}$ diperoleh kecerahan warna dengan nilai 3,9 , sedangkan pada konsentrasi larutan zat warna pigmen $10 \mathrm{~g} / \mathrm{l}$ kecerahan warna meningkat menjadi 4,8. Pada konsentrasi larutan zat warna pigmen $15 \mathrm{~g} / \mathrm{l}$ kecerahan warna tidak meningkat lagi tetapi cenderung menurun dengan nilai 4,7.

Meningkatnya nilai kecerahan warna ada hubungannya dengan jumlah molekul zat warna yang terdapat dalam kompon

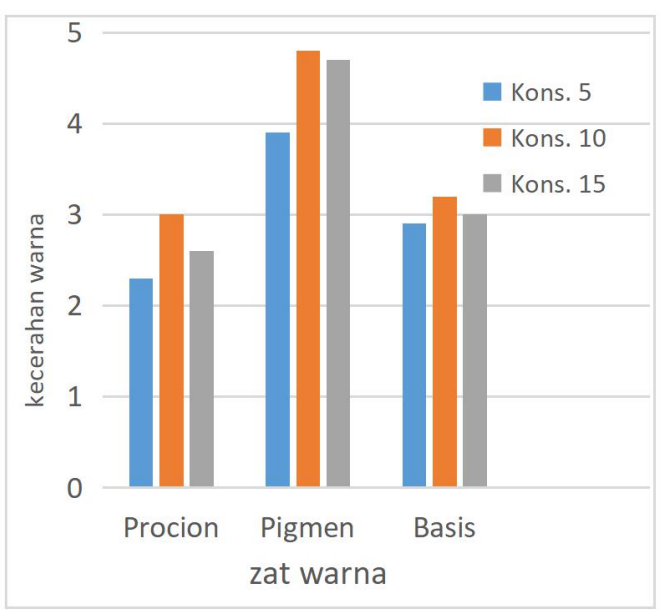

Gambar 2. Histogram Kecerahan warna

lateks, semakin besar konsentrasi larutan zat warna dalam kompon lateks maka jumlah molekul-molekul zat warna akan semakin banyak dan jumlah molekul-molekul zat warna yang mengadakan ikatan dengan molekul polyisoprene dan bahan kimia lainnya juga semakin besar sehingga warna kain kanvas yang dihasilkan warnanya semakin cerah Apabila molekul-molekul zat warna yang mengadakan ikatan kimia tersebut telah mencapai keadaan yang maksimum maka kecerahan warna yang 
dihasilkan akan berkurang dan warna yang dihasilkan semakin tua, seperti dapat dilihat pada histogram Gambar 2.

Zat warna pigmen menghasilkan kecerahan warna yang lebih tinggi dengan nilai 4,8 bila dibandingkan dengan zat warna procion dan zat warna basis dengan nilai 3,0 dan 3,2. Zat warna pigmen merupakan suatu senyawa yang inert dan stabil, mempunyai ikatan yang lebih kuat dengan molekul polyisoprene, juga dipakai sebagai pewarna untuk bahan pelapis (coating), tinta cetak, pewarna kulit, kertas dan lain-lain. Zat warna pigmen juga digunakan pada produk-produk kosmetik, sabun, malam, kapur dan polimer serat. Pada Industri tekstil zat warna pigmen banyak digunakan pada proses pencapan (printing), menghasilkan warna yang lebih cerah (Kuntari, 2009), sedangkan zat warna reaktif dan basis umumnya digunakan pada proses dyeing.

\section{Ketahanan Luntur Warna Terhadap Pencucian}

Hasil pengujian ketahanan luntur warna kain kanvas water repellent terhadap pencucian seperti terlihat pada Tabel 2, nilainya untuk masing-masing zat warna tidak berbeda nyata dengan bertambahnya konsentrasi zat warna, baik untuk zat warna procion, pigmen maupun zat warna basis.

Penilaian tahan luntur warna dilakukan dengan melihat adanya perubahan warna asli sebagai tidak ada perubahan, ada sedikit perubahan, cukup berubah dan berubah sama sekali. Standar yang digunakan adalah standar Gray Scale (perubahan warna) dan Staining scale (penodaan warna). Pada Gray Scale, penilaian tahan luntur warna dan perubahan warna dilakukan dengan membandingkan perbedaan pada contoh yang telah diuji dengan contoh asli, terhadap perbedaan yang sesuai dari deretan standar perubahan yang digambarkan oleh Gray scale. Sedangkan

pada Staining Scale penilaian penodaan pada kain putih didalam pengujian tahan luntur warna, dilakukan dengan membandingkan perbedaan warna dari kain putih yang dinodai dan yang tidak dinodai, terhadap perbedaan yang digambarkan oleh Staining Scale.(Murdoko, et al, 1007)
Ketahanan luntur warna terhadap pencucian pada zat warna procion bernilai 2 (kurang) untuk perubahan warna dan bernilai 2-3 (kurang) untuk penodaan warna, ketahanan luntur warna pada zat warna pigmen bernilai 4 (baik) untuk perubahan warna dan bernilai 4-5 (baik) untuk penodaan warna, sedangkan ketahanan luntur warna pada zat warna basis bernilai 3 (cukup) untuk perubahan warna dan bernilai 3-4 (cukup) untuk penodaan warna.

Zat warna pigmen menghasilkan ketahanan luntur warna terhadap pencucian yang lebih baik dibandingkan dengan zat warna procion dan basis baik perubahan warna maupun penodaan warna. Selama proses pembuatan kompon

berlangsung molekul-molekul zat warna pigmen yang mengadakan ikatan dengan lateks dan bahan-bahan kimia lainnya terikat lebih baik sehingga pada saat dilakukan pengujian ketahanan luntur warna terhadap pencucian molekul-molekul zat warna tidak mudah lepas.

Nilai ke.tahanan luntur warna kain kanvas terhadap pencucian seperti terlihat

Pada Tabel 2, nilainya tidak berbeda nyata

Tabel 2. Hasil uji tahan luntur warna terhadap pencucian

\begin{tabular}{lccccc}
\hline & \multicolumn{5}{c}{ Formula } \\
\cline { 2 - 6 } $\begin{array}{l}\text { Ketahanan } \\
\text { Luntur } \\
\text { warna }\end{array}$ & I & II & III & IV & V \\
\hline $\begin{array}{l}\text { Perubahan } \\
\text { warna }\end{array}$ & 2 & 2 & 2 & 4 & 4 \\
$\begin{array}{l}\text { Penodaan } \\
\text { warna }\end{array}$ & $2-3$ & $2-3$ & $2-3$ & $4-5$ & $4-5$ \\
\hline
\end{tabular}

Tabel 2 lanjutan

\begin{tabular}{lcccc}
\hline & \multicolumn{5}{c}{ Formula } \\
$\begin{array}{l}\text { Ketahanan } \\
\text { Luntur } \\
\text { warna }\end{array}$ & VI & VII & VIII & IX \\
\cline { 2 - 5 } $\begin{array}{l}\text { Perubahan } \\
\text { warna }\end{array}$ & 4 & 3 & 3 & 3 \\
\hline $\begin{array}{l}\text { Penodaan } \\
\text { warna }\end{array}$ & $4-5$ & $3-4$ & $3-4$ & $3-4$ \\
\hline
\end{tabular}

baik perubahan warna maupun penodaan warna dengan bertambahnya konsentrasi zat warna baik untuk zat warna procion, 
pigmen maupun basis, disebabkan pada proses pencucian atau penyabunan yang dilakukan setelah proses pewarnaan, molekul-molekul zat warna yang tersisa dan menempel pada permukaan kain akan berkurang atau hilang sama sekali, sehingga waktu dilakukan proses pengujian ketahanan luntur warna terhadap pencucian nilainya cenderung tetap baik perubahan warna maupun penodaan warna. (Agus, et al, 2016)

Ketahanan luntur warna terhadap pencucian tertinggi dihasilkan zat warna pigmen, dengan nilai (4) untuk perubahan warna dan 4-5 untuk penodaan warna, diperoleh pada formula IV, $\mathrm{V}$ dan $\mathrm{VI}$ dengan menggunakan zat warna pigmen konsentrasi $5 \mathrm{~g}, 10 \mathrm{~g}$ dan $15 \mathrm{~g}$

\section{Ketahanan Luntur Warna Terhadap Gosokan}

Hasil pengujian terhadap ketahanan luntur warna kain kanvas water repellent terhadap gosokan seperti terlihat pada Tabel 3 , nilainya juga tidak berbeda nyata dengan bertambahnya konsentrasi zat warna, baik untuk zat warna procion, pigmen maupun zat warna basis. Penilaian tahan luntur warna terhadap gosokan juga dilakukan dengan melihat adanya perubahan warna asli sebagai tidak ada perubahan, ada sedikit perubahan, cukup berubah dan berubah sama sekali. Standar yang digunakan adalah standar Gray Scale (perubahan warna)..

Zat warna pigmen menghasilkan nilai ketahanan luntur warna terhadap gosokan yang lebih tinggi dibandingkan dengan zat warna procion dan basis, baik untuk ketahanan luntur warna terhadap gosokan kering maupun ketahanan luntur warna terhadap gosokan basah.

Ketahanan luntur warna pada zat warna procion warna bernilai 3 (cukup) untuk gosokan kering dan bernilai 2 (kurang) untuk gosokan basah, ketahanan luntur warna pada zat warna pigmen bernilai 4-5 (baik) untuk gosokan kering dan bernilai 4 (baik) untuk gosokan basah, sedangkan ketahanan luntur warna pada zat warna basis bernilai 34 (cukup) untuk gosokan kering dan bernilai 3 (cukup) untuk gosokan basah.

Tingginya nilai ketahanan luntur warna pada gosokan kering dibanding gosokan basah disebabkan oleh proses pencucian/penyabunan, dimana semua zat warna yang menempel pada permukaan kain sudah terlepas, sehingga pada waktu proses pengujian ketahanan gosok zat warna yang berada didalam kain akan sulit terlepas (Perikh, 2010).

Tabel 3. Hasil uji tahan luntur warna terhadap gosokan

\begin{tabular}{lccccc}
\hline & \multicolumn{5}{c}{ Formula } \\
\cline { 2 - 6 } $\begin{array}{l}\text { Ketahanan } \\
\text { warna }\end{array}$ & I & II & III & IV & V \\
\cline { 2 - 6 } $\begin{array}{l}\text { Gosokan } \\
\text { kering }\end{array}$ & 3 & 3 & 3 & $4-5$ & $4-5$ \\
\hline $\begin{array}{l}\text { Gosokan } \\
\text { basah }\end{array}$ & 2 & 2 & 2 & 4 & 4 \\
\hline
\end{tabular}

Tabel 3. lanjutan

\begin{tabular}{lcccc}
\hline & \multicolumn{5}{c}{ Formula } \\
\cline { 2 - 5 } $\begin{array}{l}\text { Ketahanan } \\
\text { warna }\end{array}$ & VI & VII & VIII & IX \\
\cline { 2 - 5 } $\begin{array}{l}\text { Gosokan } \\
\text { kering }\end{array}$ & $4-5$ & $3-4$ & $3-4$ & $3-4$ \\
\hline $\begin{array}{l}\text { Gosokan } \\
\text { basah }\end{array}$ & 4 & 3 & 3 & 3 \\
\hline
\end{tabular}

Pada gosokan basah adanya air menyebabkan kain menggelembung dan pori-pori akan membuka, mengakibatkan zat warna yang ada mudah keluar dan dengan adanya gesekan atau gerakan mekanik langsung dari alat uji mengakibatkan sebagian zat warna yang terikat akan terlepas dan menempel pada kain penggosok.(Hakeim, 2015)

Ketahanan luntur warna terhadap gosokan tertinggi dengan nilai 4-5 (baik) gosokan kering dan nilai 4 (baik) untuk gosokan basah diperoleh pada formula IV, $\mathrm{V}$ dan VI dengan menggunakan zat warna pigmen konsentrasi $5 \mathrm{~g}, 10 \mathrm{~g}$ dan $15 \mathrm{~g}$

\section{Daya Tahan Air}

Uji daya tahan air merupakan uji permukaan kain yang dapat menahan air dan merupakan uji fisika yang paling penting dalam menentukan kualitas kain kanvas water repellent. Hasil pengujian terhadap daya tahan air seperti dapat dilihat pada Gambar 3, menunjukkan bahwa penggunaan zat warna procion, pigmen dan basis pada lateks alam sebagai bahan pelapis pada pembuatan kain kanvas water repellent nilainya juga tidak berbeda nyata, walaupun 
ada peningkatan untuk zat warna pigmen dan penurunan untuk zat warna procion dan basis dengan meningkatnya konsentrasi zat warna.

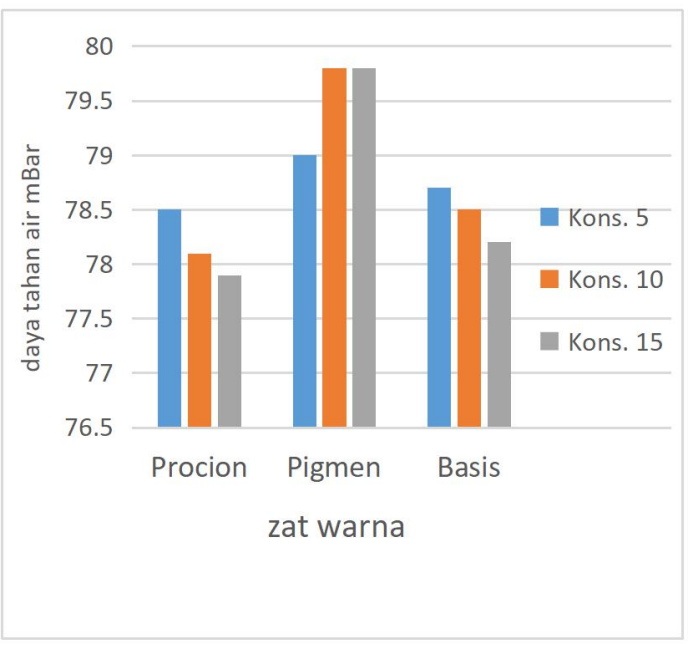

Gambar 3..Histogram daya tahan air

Kompon lateks merupakan campuran bahan lateks yang sudah melalui proses sentrifugasi dengan bahan-bahan kimia yang sudah dilakukan proses disperse antara lain ZDEC, ZMBT, ZnO, lonol, Sulfur/belerang dan zat warna.

Bahan kimia ZDEC dan ZMBT merupakan bahan kimia yang berfungsi sebagai bahan pencepat, $\mathrm{ZnO}$ sebagai bahan activator, sulfur merupakan bahan untuk vulkanisasi dan ionol sebagai bahan anti oksidan, sedangkan zat warna dicampurkan pada kompon lateks berfungsi untuk memberi warna pada produk karet yang bukan hitam (Sasidharan, et al, 2007)

Histogram pada Gambar 3. dapat dilihat bahwa pada konsentrasi larutan zat warna pigmen $5 \mathrm{~g} / \mathrm{l}$ diperoleh daya tahan air dengan nilai 79 mBar, sedangkan pada konsentrasi larutan zat warna pigmen $10 \mathrm{~g} / \mathrm{l}$ daya tahan air meningkat menjadi 79,8 mBar. Pada konsentrasi larutan zat warna pigmen $15 \mathrm{~g} / \mathrm{l}$ daya tahan air tidak meningkat lagi tetapi cenderung tetap dengan nilai 79.8 mBar. Walaupun ada peningkatan dan penurunan nilai daya tahan air untuk masing-masing zat warna dengan meningkatkan konsentrasi setiap penggunaan zat warna, nilai daya tahan airnya tidak berbeda nyata dengan demikian zat warna tidak mempengaruhi sifat fisika daya tahan airnya.
Daya tahan air tertinggi 79,8 mBar diperoleh pada formula $\mathrm{V}$ dan $\mathrm{VI}$ dengan menggunakan zat warna pigmen konsentrasi $10 \mathrm{~g}$ dan $15 \mathrm{~g}$.

\section{Kekuatan Rekat}

Kekuatan rekat menggambarkan kecocokan antara bahan pelapis dengan bahan kain yang digunakan yaitu kain kanvas atau daya adhesi dan kohesi serta juga menggambarkan daya tahan produk hasil pelapisan selama pemakaian (Kuntari dan Astawa, 2010)

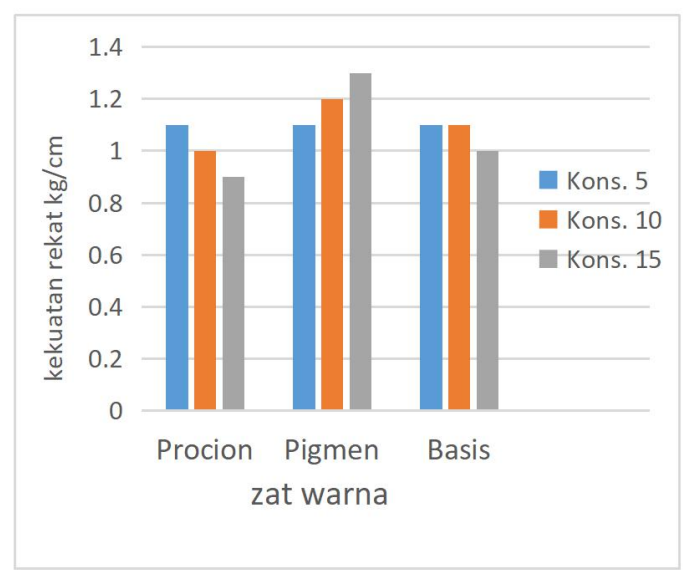

Gambar 4. Histogram Kekuatan Rekat

Hasil pengujian kekuatan rekat, seperti dapat dilihat pada Gambar 4, Kekuatan rekat sampai pada batas tertentu nilainya cenderung meningkat tetapi tidak berbeda nyata dengan bertambahnya konsentrasi zat warna, baik untuk zat warna procion, pigmen maupun zat warna basis.

Histogram pada Gambar 4 dapat dilihat bahwa pada konsentrasi larutan zat warna pigmen $5 \mathrm{~g} / \mathrm{l}$ diperoleh kekuatan rekat dengan nilai $1,1 \mathrm{~kg} / \mathrm{cm}$, sedangkan pada konsentrasi larutan zat warna pigmen $10 \mathrm{~g} / \mathrm{l}$ kekuatan rekat meningkat menjadi $1,2 \mathrm{~kg} / \mathrm{cm}$ Pada konsentrasi larutan zat warna pigmen $15 \mathrm{~g} / \mathrm{l}$ kekuatan rekat meningkat lagi dengan nilai $1,3 \mathrm{~kg} / \mathrm{cm}$. Meningkatnya nilai kekuatan rekat antara kompon lateks dengan permukaan kain kanvas ada hubungannya dengan molekul isoprene pada kompon lateks yang mengadakan ikatan dengan serat pada kain. Semakin tinggi konsentrasi 
zat warna yang digunakan pada kompon lateks, maka molekul-molekul isoprene yang terserap dan mengadakan ikatan dengan serat pada kain semakin bertambah sehingga daya rekatnya cenderung bertambah tetapi tidak berbeda nyata.

Kekuatan rekat kain kanvas water repellent tertinggi $1,3 \mathrm{~kg} / \mathrm{cm}$ diperoleh pada formula VI dengan menggunakan zat warna pigmen konsentrasi $15 \mathrm{~g}$.

\section{Kekuatan Tarik dan Mulur}

Kekuatan tarik dan mulur merupakan tenaga yang dibutuhkan untuk menarik bahan kain kanvas water repellent sampai putus dan merupakan pengujian fisika kain kanvas yang sangat penting dan sering dilakukan.

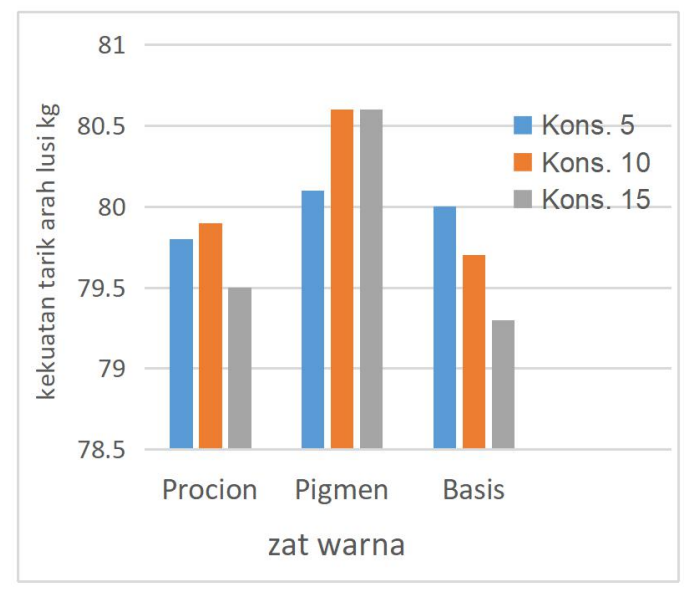

Gambar 5. Histogram Kekuatan tarik arah lusi

Hasil pengujian sifat fisika kain kanvas water repellent terhadap kekuatan tarik dan mulur seperti dapat dilihat pada Gambar 5, Gambar 6, Gambar 7 dan Gambar 8, kekuatan tarik dan mulur nilainya tidak bebeda nyata walaupun ada sedikit peningkatan untuk zat warna pigmen dan penurunan untuk zat warna procion dan basis dengan meningkatnya konsentrasi zat warna, baik terhadap kekuatan tarik arah lusi dan kekuatan tarik arah pakan serta mulur arah lusi maupun mulur arah pakan.

Histogram kekuatan tarik arah lusi pada Gambar 5 dapat dilihat bahwa pada konsentrasi larutan zat warna pigmen $5 \mathrm{~g} / \mathrm{l}$ diperoleh kekuatan tarik dengan nilai $80,1 \mathrm{~kg}$, sedangkan pada konsentrasi larutan

zat warna pigmen $10 \mathrm{~g} / \mathrm{l}$ kekuatan tarik meningkat menjadi $80,6 \mathrm{~kg}$. Pada konsentrasi larutan zat warna pigmen $15 \mathrm{~g} / \mathrm{l}$ kekuatan tarik tidak meningkat lagi tetapi cenderung tetap dengan nilai $80,6 \mathrm{~kg} / \mathrm{cm}$. Histogram kekuatan tarik arah pakan pada Gambar 6 dapat dilihat bahwa pada konsentrasi larutan zat warna pigmen $5 \mathrm{~g} / \mathrm{l}$ diperoleh kekuatan tarik dengan nilai $77,5 \mathrm{~kg}$, sedangkan pada konsentrasi larutan zat warna pigmen $10 \mathrm{~g} / \mathrm{l}$ kekuatan tarik meningkat menjadi 77,8

kg. Pada konsentrasi larutan zat warna pigmen $15 \mathrm{~g} / \mathrm{l}$ kekuatan tarik meningkat lagi dengan nilai $78,1 \mathrm{~kg}$.

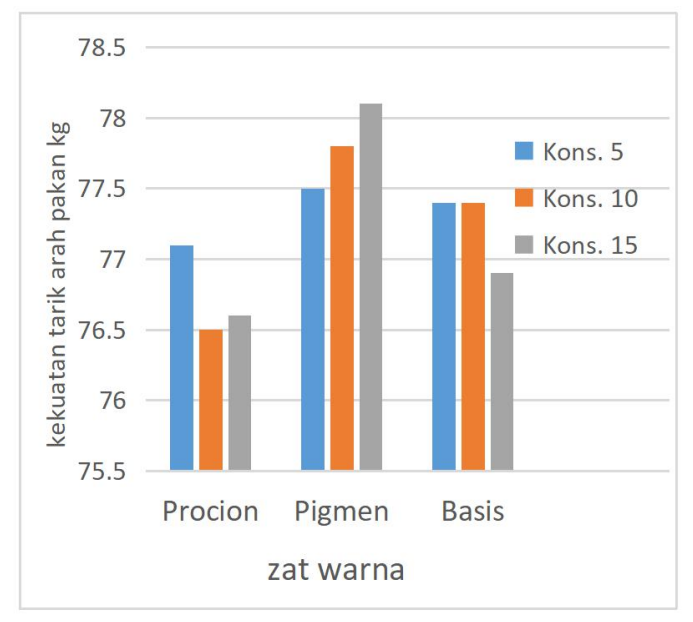
Gambar 6. Histogram Kekuatan tarik arah
pakan

Histogram mulur arah lusi pada Gambar 7 dapat dilihat bahwa pada konsentrasi larutan zat warna pigmen $5 \mathrm{~g} / \mathrm{l}$ diperoleh mulur dengan nilai 40,7 \%, sedangkan pada konsentrasi larutan zat warna pigmen $10 \mathrm{~g} / \mathrm{l}$ kekuatan tarik meningkat menjadi $41,2 \%$, pada konsentrasi larutan zat warna pigmen $15 \mathrm{~g} / \mathrm{l}$ mulur tidak meningkat lagi tetapi cenderung tetap dengan nilai $40,9 \%$. Histogram mulur arah pakan pada Gambar 8 dapat dilihat bahwa pada konsentrasi larutan zat warna pigmen $5 \mathrm{~g} / \mathrm{l}$ diperoleh mulur dengan nilai $18,5 \% \%$, sedangkan pada konsentrasi larutan zat warna pigmen

$10 \mathrm{~g} / \mathrm{l}$ kekuatan tarik meningkat menjadi 18,8 $\%$, pada konsentrasi larutan zat warna.

Zat warna bukan suatu bahan kimia pengisi aktif atau tidak aktif pada kompon lateks tetapi merupakan bahan khusus yang berfungsi sebagai bahan pewarna pada kompon lateks, dengan adanya peningkatan konsentrasi zat warna baik zat warna procion, pigmen maupun basis berarti tidak terjadi peningkatan interaksi antara molekul-molekul zat warna dengan molekul isoprene pada kompon lateks sehingga kekuatan tarik kain 
dan mulur kanvas nilainya tidak berbeda nyata baik kekuatan tarik kain arah lusi maupun kekuatan tarik kain arah pakan serta mulur arah lusi maupun mulur arah pakan.(Ahmad, et al, 2012)

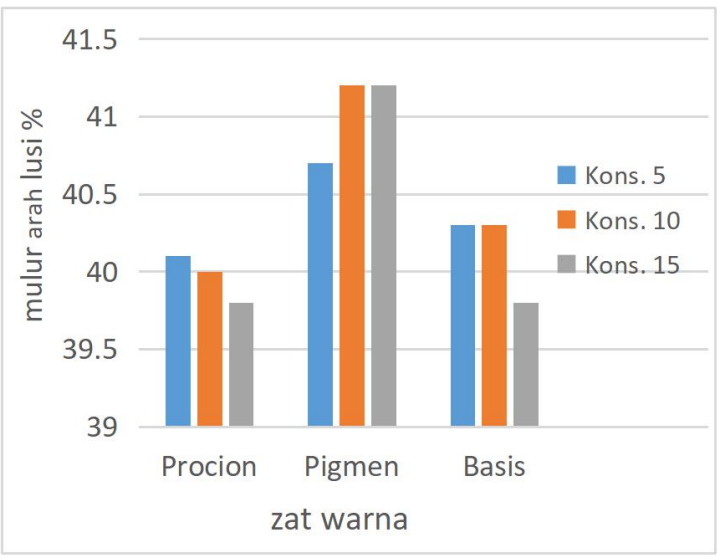

Gambar 7. Histogram mulur kain arah lusi

pigmen $15 \mathrm{~g} / \mathrm{l}$ mulur tidak meningkat lagi tetapi cenderung menurun dengan nilai 18,7 $\%$.

Kekuatan tarik kain kanvas tertinggi,yaitu $80,6 \mathrm{~kg}$ untuk arah lusi dan $78,1 \mathrm{~kg}$ untuk arah pakan diperoleh pada formula $\mathrm{V}$ dan $\mathrm{VI}$ menggunakan zat warna pigmen konsentrasi $10 \mathrm{~g}$ dan $15 \mathrm{~g}$, mulur kain kanvas tertinggi, yaitu $41,2 \%$ untuk arah lusi dan $18,9 \%$ untuk arah pakan diperoleh pada formula $\mathrm{V}$ dan $\mathrm{VI}$ menggunakan zat warna pigmen konsentrasi 10 dan $15 \mathrm{~g}$.

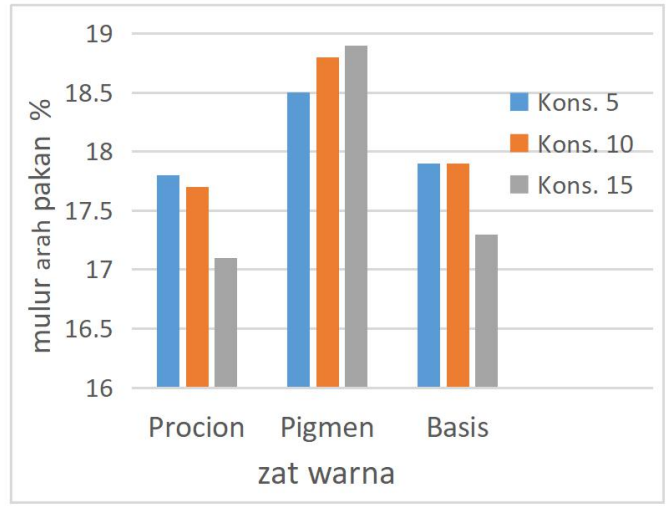

Gambar 8. Histogram mulur kain arah pakan

\section{Kekuatan Sobek}

Kekuatan sobek merupakan tenaga yang dibutuhkan untuk merobek bahan kain kanvas dan merupakan pengujian fisika kain kanvas yang cukup penting dan sering dilakukan disamping kekuatan tarik dan mulur.

Hasil pengujian sifat fisika kain kanvas water repellent terhadap kekuatan sobek seperti dapat dilihat pada Gambar 9 dan Gambar 10, nilai kekuatan sobek cenderung tidak bebeda nyata walaupun ada peningkatan untuk zat warna pigmen dan penurunan untuk zat warna procion dan basis dengan meningkatnya konsentrasi zat warna, baik terhadap kekuatan sobek arah lusi maupun kekuatan sobek arah pakan.

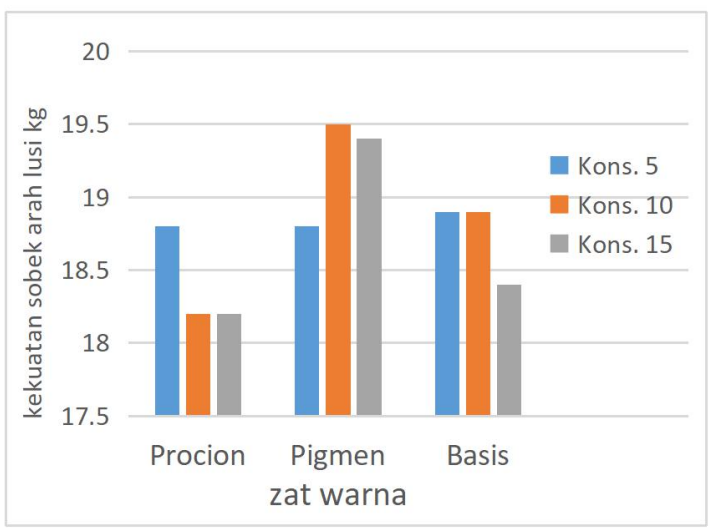

Gambar 9. Histogram Kekuatan sobek arah lusi

Histogram kekuatan sobek arah lusi pada Gambar 9 dapat dilihat bahwa pada konsentrasi larutan zat warna pigmen $5 \mathrm{~g} / \mathrm{l}$ diperoleh kekuatan sobek dengan nilai 18,8 $\mathrm{kg}$, sedangkan pada konsentrasi larutan zat warna pigmen $10 \mathrm{~g} / \mathrm{l}$ kekuatan sobek meningkat menjadi $19,5 \mathrm{~kg}$, pada konsentrasi larutan zat warna pigmen $15 \mathrm{~g} / \mathrm{l}$ kekuatan sobek tidak meningkat lagi tetapi cenderung menurun dengan nilai 19,4 kg.

Histogram kekuatan sobek arah pakan pada Gambar 10 dapat dilihat bahwa pada konsentrasi larutan zat warna pigmen $5 \mathrm{~g} / \mathrm{l}$ diperoleh kekuatan sobek dengan nilai 18,0 $\mathrm{kg}$, sedangkan pada konsentrasi larutan zat warna pigmen $10 \mathrm{~g} / \mathrm{l}$ kekuatan sobek meningkat menjadi $18,2 \mathrm{~kg}$, pada konsentrasi larutan zat warna pigmen $15 \mathrm{~g} / \mathrm{l}$ kekuatan sobek tidak meningkat lagi tetapi cenderung tetap dengan nilai 18,2 kg. Menurun dan naiknya kekuatan sobek kain kanvas water repellent baik arah lusi 


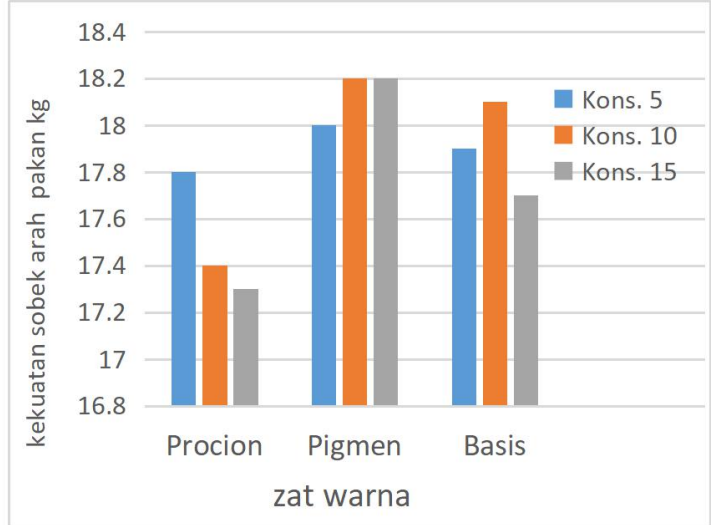

Gambar 10. Histogram Kekuatan sobek arah pakan

maupun arah pakan tergantung kepada pertambahan dan kerapatan ikatan silang vulkanisat karet, semakin rapat ikatan silang, maka kekuatan sobek semakin meningkat, demikian pula sebaliknya (Hassim, et al, 2011).

Hasil pengujian menunjukkan bahwa nilai kekuatan sobek kain kanvas water repellent baik arah lusi maupun arah pakan nilainya tidak berbeda nyata yang berarti meningkatkan konsentrasi zat warna procion, pigmen maupun basis tidak mempengaruhi kerapatan ikatan kompon karetnya..

Kekuatan sobek kain kanvas tertinggi, yaitu 19,5 kg untuk arah lusi dan 18,2 kg untuk arah pakan diperoleh pada formula $\mathrm{V}$ dan VI menggunakan zat warna pigmen konsentrasi 10 g.dan $15 \mathrm{~g}$.

\section{KESIMPULAN}

Zat warna tekstil dapat digunakan sebagai bahan pewarna pada campuran lateks alam dan bahan kimia lainnya pada pembuatan kain kanvas water repellent, peningkatan jumlah penggunaan bahan pewarna pada pembuatan kompon lateks pada batas tertentu dapat meningkatkan kecerahan warna kain kanvas water repellent, tetapi ketahanan luntur warna terhadap pencucian dan gosokan dan sifat fisika lainnya seperti daya tahan air, kekuatan rekat, kekuatan tarik, mulur dan kekuatan sobek kainnya cenderung tidak berbeda nyata. Hasil terbaik diperoleh pada formula $V$ menggunakan zat warna pigmen dengan konsentrasi $10 \mathrm{~g}$. Perlu dilakukan penelitian lebih lanjut pembuatan kain kanvas water repellent menggunakan zat warna jenis lain seperti zat warna asam, direk, naphtol dan disperse.

\section{UCAPAN TERIMA KASIH}

Penulis menyampaikan terima kasih kepada Kepala Baristand Industri Palembang, rekan-rekan Tim Riset, Dewan Redaksi, Mitra Bestari dan Redaksi Pelaksana atas terlaksananya penelitian dan terbitnya tulisan ini

\section{DAFTAR PUSTAKA}

Agus T, Riski AN dan Nisrina QA (2016)

Penggunaan Cap Bebas Minyak pada Pencapan Kain Kapas dengan Zat Warna Pigmen, Jurnal Teknoin Vol. 22 (11) : 804-819

Ahmad, MR, Nuwatif, A, \& Soraya, AS (2012), Tensile and Tearing of uncoated and Nature Rubber Latex Coated High Strength Woven Fabrics, IEE Sympesium of Humanites, Science and Engineering Research

Badan Standardisasi Nasional, (1989), SNI. 08-0276-89 Cara Uji Kekuatan Tarik dan Mulur Kain, Dewan Standardisasi Nasional, Jakarta

Badan Standardisasi Nasional, (1989), SNI. 08-0285-89 Cara Uji Tahan Luntur Terhadap Pencucian, Dewan Standardisasi Nasional, Jakarta

Badan Standardisasi Nasional, (1989), SNI. 08-0288-89, Cara Uji Tahan Luntur Terhadap Gosokan, Dewan Standardisasi Nasional, Jakarta

Badan Standardisasi Nasional, (1989), SNI. 08-0295-89, Cara Uji Tahan Air/Uji Tekanan Hidrostatik Kain, Dewan Standardisasi Nasional, Jakarta

Badan Standardisasi Nasional, (1989), SNI. 08-0338-89, Cara Uji Ketahanan Sobek Kain, Dewan Standardisasi Nasional, Jakarta

Blackley, DC (2011), High Polymer Latice, New York, Maclaren and sons

Djufri, R, Kasunarno dan Salihima, (1998), Teknologi

Pengelantangan, Pencelupan dan Pencapan, Bandung, Sekolah Tinggi Teknologi Tekstil.

Hakeim, M (2015), Anti Static and Fungtional Properties of Asminosilsesquioxane 
Oligomer Treated and Dye Fabrics, Journal Of The Textile Association, 90101

Hartanto,NS. Dan Watanabe, S.( 2003). Teknologi Tekstil, Jakarta, Paradnya Paranita.

Hassim N, Ahmad MR Yahya (2011), Puncture Resistance of Natural Rubber Latex Unidirectional Coated Fabrics, Journal of Industrial Textile 40 (3): 420429

Hudson T, (2011) The Fashion Designer's Textile Directory London: Quarto Publishing, Inc

International Organization for Standardization (2017), ISO 2411 Kain Berlapis Karet atau Plastik Penentuan Adhesi Lapisan.

Kuntari (2009), Penelitian pasta Emulsi Minasol M, Pertasol CA dan Pertasol CB pada Pencapan Kain Selulosa dengan Zat warna Pigmen, Indonesia Journal of Material Science, Vol. 8 halaman 173-181

Kuntari dan Astawa. GP (2010) Proses Finishing Kain Payung Nylon 66 Mempergunakan Resin Fluorokarbon (Water Repellent Agen) dan estert asam Poliakrilat (Coating Agent).

Luftinor, (2015), Penggunaan lateks alam cair Sebagai Bahan Pelapis Kain kanvas Water Repellent, Prosiding Workshop Litbang Unggulan, Kementerian Perindustrian

Morton, M, (2008), Introduction of Rubber Technologi, New York, Reinhold Publishing Corporation

Mohamed, M, (2017) Properties of Cellulosic FabricTreated by Water RepellentEmulsions, Indian Jurnal of Fiber and Textile Research 42, 223-229

Murdoko W, Isminingsih, Wagimun dan Suripto (1997), Evaluasi Tekstil Fisika, Sekolah Tinggi Teknologi Tekstil

Noble, RJ (2003), Latex In Industry,Connecticut, Palmerton Publishing Co. Inc.

Perikh DV (2010), Pigmen Printing to Textile, American Dyestuff Reporter Volume 59.

Richard, S. (2009), Latex Technology, London, John Willey and Sons Inc.

Sasidharan, KK, Joseph, R, Palaty, S and Pillai, PV (2007), Effect of vulcanization time and storage on the stability and physical properties of sulfur prevulcanized natural rubber latex, Journal of Applied Polimer science, 97 (1): 1804-1812

Stagg, R (2007), Latex Technology. John Wiley and Sons Inc.

Stevens, HP dan Stevens, WH (2006), Rubber Latex, London, The Rubber Grouwers Association Inc

Sunarto, (2008), Teknologi Pencelupan dan Pencapan, Jakarta, Departemen pendidikan Nasional

Suparman, Surdia, NM dan Budiarti, (1997), Teknologi Penyempurnaan Tekstil, Bandung, Sekolah Tinggi Teknologi Tekstil Sundari Umayal A.R., Neelamegam P., Subramanian C.V., (2013), Performance of Evacuated Tube Collector Solar Dryer with and without Heat Sources, Iranica Journal of Energy \& Environment 4 (4): 336342. 